KYUNGPOOK Math. J. 54(2014), 375-385

http://dx.doi.org/10.5666/KMJ.2014.54.3.375

\title{
Halpern's Iteration for Strongly Relatively Nonexpansive Mappings in Banach Spaces
}

\author{
Suthep SuAntai \\ Department of Mathematics, Faculty of Science, Chiang Mai University, Chiang \\ Mai 50200, Thailand \\ e-mail : scmti005@chiangmai.ac.th \\ Prasit CholamjiaK* \\ School of Science, University of Phayao, Phayao 56000, Thailand \\ e-mail : prasitch2008@yahoo.com
}

ABSTRACT. We investigate strong convergence of Halpern's iteration for a countable family of strongly relatively nonexpansive mappings in the framework of uniformly convex and uniformly smooth Banach spaces. Our results extend those announced by many authors.

\section{Introduction}

Let $C$ be a nonempty, closed and convex subset of a real Banach space $E$. Let $T: C \rightarrow C$ be a nonlinear mapping. The fixed points set of $T$ is denoted by $F(T)$, that is, $F(T)=\{x \in C: x=T x\}$. A mapping $T$ is said to be nonexpansive if $\|T x-T y\| \leq\|x-y\|$ for all $x, y \in C$.

In recent years, several types of iterative schemes have been constructed and proposed in order to get strong convergence results for nonexpansive mappings in various setting. One classical and effective iteration process is defined as follows: $x_{1}, u \in C$ and

$$
x_{n+1}=\alpha_{n} u+\left(1-\alpha_{n}\right) T x_{n}, \quad \forall n \geq 1,
$$

where $\left\{\alpha_{n}\right\} \subset(0,1)$. Such a method is introduced, in 1967, by Halpern [8] and later is often called Halpern's iteration. In fact, he proved, in a real Hilbert space, the strong convergence of $\left\{x_{n}\right\}$ to a fixed point of a nonexpansive mapping $T$, where $\alpha_{n}=n^{-a}, a \in(0,1)$.

* Corresponding Author.

Received June 18, 2011; accepted March 27, 2013.

2010 Mathematics Subject Classification: 47H09, 47H10.

Key words and phrases: Strongly relatively nonexpansive mapping, Banach space, generalized projection, Halpern's iteration, strong convergence theorem. 
Now, because of a simple construction, Halpern's iteration is widely used to approximate a solution of fixed points for nonexpansive mappings and other classes of nonlinear mappings by mathematicians in different styles.

In 1977, Lions [11] obtained a strong convergence provide the real sequence $\left\{\alpha_{n}\right\}$ satisfies the following conditions:

C1: $\lim _{n \rightarrow \infty} \alpha_{n}=0$; C2: $\sum_{n=1}^{\infty} \alpha_{n}=\infty ;$ C3: $\lim _{n \rightarrow \infty} \frac{\alpha_{n+1}-\alpha_{n}}{\alpha_{n+1}^{2}}=0$.

Reich [17] also extended the result of Halpern from Hilbert spaces to uniformly smooth Banach spaces. However, both Halpern's and Lions' conditions imposed on the real sequence $\left\{\alpha_{n}\right\}$ exclude the canonical choice $\alpha_{n}=1 / n$ for all $n \in \mathbb{N}$.

Subsequently, Wittmann [23] overcome the problem mentioned above by proving the strong convergence of $\left\{x_{n}\right\}$ if $\left\{\alpha_{n}\right\}$ satisfies the conditions C1, C2 and C4:

$$
\sum_{n=1}^{\infty}\left|\alpha_{n+1}-\alpha_{n}\right|<\infty .
$$

In 1997, Shioji-Takahshi [20] extended Wittmann's result from Hilbert spaces to real Banach spaces with uniformly Gâteaux differentiable norms and in which each nonempty closed convex and bounded subset has the fixed point property for nonexpansive mappings.

In 2002, Xu [24] introduced another control condition C5: $\frac{\alpha_{n+1}-\alpha_{n}}{\alpha_{n+1}} \rightarrow 0$ instead of the conditions C3 or C4 and proved the strong convergence of the sequence $\left\{x_{n}\right\}$.

In 2005, Cho et al. [7] pointed out that the control conditions C4 and C5 are not comparable, in general. They gave some examples which satisfy the conditions $\mathrm{C} 1, \mathrm{C} 2, \mathrm{C} 3, \mathrm{C} 4$ and $\mathrm{C} 5$, and also presented the control condition C6:

$$
\left|\alpha_{n+1}-\alpha_{n}\right| \leq \circ\left(\alpha_{n+1}\right)+\sigma_{n},
$$

where $\sum_{n=1}^{\infty} \sigma_{n}<\infty$. This includes the conditions C3, C4 and C5 as special cases. A countable version of Halpern's iteration for nonexpansive mappings has been studied in [3].

One question arises in literature naturally: Is it possible to get strong convergence of (1.1) when the sequence $\left\{\alpha_{n}\right\}$ satisfies only the conditions C1 and C2?

Recently, Chidume-Chidume [6] and Suzuki [21] independently gave an affirmative answer to the above question. To be more precise, they introduced the following Halpern-type iteration: $x_{1}, u \in C$ and

$$
x_{n+1}=\alpha_{n} u+\left(1-\alpha_{n}\right)\left(\lambda x_{n}+(1-\lambda) T x_{n}\right), \quad \forall n \geq 1,
$$

and obtained strong convergence results for the sequence $\left\{x_{n}\right\}$ generated by $(1.2)$ when only the conditions $\mathrm{C} 1$ and $\mathrm{C} 2$ are imposed on the sequence $\left\{\alpha_{n}\right\}$.

Very recently, Saejung [19] focused in studying Halpern's iteration for an important subclass of nonexpansive mappings which is the so-called strongly nonexpansive [4], i.e., a mapping $T: C \rightarrow C$ satisfying $T$ is nonexpansive and

$$
x_{n}-y_{n}-\left(T x_{n}-T y_{n}\right) \rightarrow 0
$$


whenever $\left\{x_{n}\right\}$ and $\left\{y_{n}\right\}$ are sequences in $C$ such that $\left\{x_{n}-y_{n}\right\}$ is bounded and

$$
\left\|x_{n}-y_{n}\right\|-\left\|T x_{n}-T y_{n}\right\| \rightarrow 0 .
$$

He proved that the sequence generated by Halpern's iteration converges strongly to a fixed point of $T$ if the sequence $\left\{\alpha_{n}\right\} \subset(0,1)$ just satisfies the conditions $\mathrm{C} 1$ and $\mathrm{C} 2$. This shows that a class of strongly nonexpansive mappings works for Halpern's iteration with the conditions $\mathrm{C} 1$ and $\mathrm{C} 2$.

The purpose of this work is to investigate strong convergence for a strongly relatively nonexpansive mapping in a uniformly convex and uniformly smooth Banach space. We obtain a strong convergence theorem when $\left\{\alpha_{n}\right\}$ satisfies only $\mathrm{C} 1$ and $\mathrm{C} 2$.

\section{Preliminaries and Lemmas}

In this section, we begin by recalling some preliminaries and lemmas which will be used in the proof.

Let $E$ be a real Banach space and let $U=\{x \in E:\|x\|=1\}$ be the unit sphere of $E$. A Banach space $E$ is said to be strictly convex if for any $x, y \in U$,

$$
x \neq y \text { implies }\left\|\frac{x+y}{2}\right\|<1 .
$$

It is also said to be uniformly convex if for each $\varepsilon \in(0,2]$, there exists $\delta>0$ such that for any $x, y \in U$,

$$
\|x-y\| \geq \varepsilon \text { implies }\left\|\frac{x+y}{2}\right\|<1-\delta .
$$

It is known that a uniformly convex Banach space is reflexive and strictly convex. Define a function $\delta:[0,2] \rightarrow[0,1]$ called the modulus of convexity of $E$ as follows:

$$
\delta(\varepsilon)=\inf \left\{1-\left\|\frac{x+y}{2}\right\|: x, y \in E,\|x\|=\|y\|=1,\|x-y\| \geq \varepsilon\right\} .
$$

Then $E$ is uniformly convex if and only if $\delta(\varepsilon)>0$ for all $\varepsilon \in(0,2]$. A Banach space $E$ is said to be smooth if the limit

$$
\lim _{t \rightarrow 0} \frac{\|x+t y\|-\|x\|}{t}
$$

exists for all $x, y \in U$. It is also said to be uniformly smooth if the limit (2.1) is attained uniformly for $x, y \in U$. The normalized duality mapping $J: E \rightarrow 2^{E^{*}}$ is defined by

$$
J(x)=\left\{x^{*} \in E^{*}:\left\langle x, x^{*}\right\rangle=\|x\|^{2}=\left\|x^{*}\right\|^{2}\right\}
$$

for all $x \in E$. It is also known that if $E$ is uniformly smooth, then $J$ is uniformly norm-to-norm continuous on each bounded subset of $E$; see [22] for more details. 
Let $E$ be a smooth Banach space. The function $\phi: E \times E \rightarrow \mathbb{R}$ is defined by

$$
\phi(x, y)=\|x\|^{2}-2\langle x, J y\rangle+\|y\|^{2}
$$

for all $x, y \in E$.

Remark 2.1. We know the following: for each $x, y, z \in E$,

(i) $(\|x\|-\|y\|)^{2} \leq \phi(x, y) \leq(\|x\|+\|y\|)^{2}$;

(ii) $\phi(x, y)=\phi(x, z)+\phi(z, y)+2\langle x-z, J z-J y\rangle$;

(iii) $\phi(x, y)=\|x-y\|^{2}$ in a real Hilbert space.

Let $C$ be a closed and convex subset of $E$ and let $T$ be a mapping from $C$ into itself. A point $p$ in $C$ is said to be an asymptotic fixed point of $T[5,18]$ if $C$ contains a sequence $\left\{x_{n}\right\}$ which converges weakly to $p$ such that $\lim _{n \rightarrow \infty}\left\|x_{n}-T x_{n}\right\|=0$. The set of asymptotic fixed point of $T$ will be denoted by $\hat{F}(T)$. A mapping $T$ is said to be relatively nonexpansive $[13,14]$ if $\hat{F}(T)=F(T)$ and $\phi(p, T x) \leq \phi(p, x)$ for all $p \in F(T)$ and $x \in C$. A mapping $T$ is said to be strongly relatively nonexpansive [2] if $T$ is relatively nonexpansive and

$$
\lim _{n \rightarrow \infty} \phi\left(T x_{n}, x_{n}\right)=0
$$

whenever $\left\{x_{n}\right\}$ is a bounded sequence in $C$ such that

$$
\lim _{n \rightarrow \infty}\left(\phi\left(p, x_{n}\right)-\phi\left(p, T x_{n}\right)\right)=0
$$

for $p \in F(T)$. A sequence of mappings $\left\{T_{n}\right\}_{n=1}^{\infty}$ is said to be strongly relatively nonexpansive if $T_{n}$ is relatively nonexpansive for all $n \geq 1$ and

$$
\lim _{n \rightarrow \infty} \phi\left(T_{n} x_{n}, x_{n}\right)=0
$$

whenever $\left\{x_{n}\right\}$ is a bounded sequence in $C$ such that

$$
\lim _{n \rightarrow \infty}\left(\phi\left(p, x_{n}\right)-\phi\left(p, T_{n} x_{n}\right)\right)=0
$$

for $p \in \cap_{n=1}^{\infty} F\left(T_{n}\right)$.

Lemma 2.2.([14]) Let $E$ be a smooth and strictly convex Banach space and let $C$ be a nonempty, closed and convex subset of $E$. Let $T$ be a mapping from $C$ into itself such that $F(T)$ is nonempty and $\phi(u, T x) \leq \phi(u, x)$ for all $(u, x) \in F(T) \times C$. Then $F(T)$ is closed and convex.

Lemma 2.3.([9]) Let $E$ be a uniformly convex and smooth Banach space and let $\left\{x_{n}\right\}$ and $\left\{y_{n}\right\}$ be sequences of $E$ such that $\left\{x_{n}\right\}$ or $\left\{y_{n}\right\}$ is bounded and $\lim _{n \rightarrow \infty} \phi\left(x_{n}, y_{n}\right)=0$. Then $\lim _{n \rightarrow \infty}\left\|x_{n}-y_{n}\right\|=0$.

Let $E$ be a reflexive, strictly convex and smooth Banach space and let $C$ be a nonempty, closed and convex subset of $E$. The generalized projection mapping, 
introduced by Alber [1], is a mapping $\Pi_{C}: E \rightarrow C$, that assigns to an arbitrary point $x \in E$ the minimum point of the functional $\phi(y, x)$, that is, $\Pi_{C} x=\bar{x}$, where $\bar{x}$ is the solution to the minimization problem

$$
\phi(\bar{x}, x)=\min \{\phi(y, x): y \in C\} .
$$

In fact, we have the following result.

Lemma 2.4.([1]) Let $C$ be a nonempty, closed and convex subset of a reflexive, strictly convex, and smooth Banach space $E$ and let $x \in E$. Then, there exists a unique element $x_{0} \in C$ such that $\phi\left(x_{0}, x\right)=\min \{\phi(z, x): z \in C\}$.

Lemma 2.5.([1],[9]) Let $C$ be a nonempty, closed and convex subset of a reflexive, strictly convex and smooth Banach space $E, x \in E$, and $z \in C$. Then $z=\Pi_{C} x$ if and only if

$$
\langle J x-J z, y-z\rangle \leq 0, \quad \forall y \in C .
$$

Lemma 2.6.([1],[9]) Let $C$ be a nonempty, closed and convex subset of a reflexive, strictly convex and smooth Banach space $E$ and let $x \in E$. Then

$$
\phi\left(y, \Pi_{C} x\right)+\phi\left(\Pi_{C} x, x\right) \leq \phi(y, x) \quad \forall y \in C .
$$

Lemma 2.7.([2]) Let $E$ be a uniformly convex and uniformly smooth Banach space and $C$ a nonempty, closed and convex subset of $E$. Then $\Pi_{C}$ is uniformly norm-tonorm continuous on every bounded set.

We make use of the following mapping $V$ studied in Alber [1]:

$$
V\left(x, x^{*}\right)=\|x\|^{2}-2\left\langle x, x^{*}\right\rangle+\left\|x^{*}\right\|^{2}
$$

for all $x \in E$ and $x^{*} \in E^{*}$, that is, $V\left(x, x^{*}\right)=\phi\left(x, J^{-1}\left(x^{*}\right)\right)$.

Lemma 2.8.([10]) Let $E$ be a reflexive, strictly convex and smooth Banach space. Then

$$
V\left(x, x^{*}\right)+2\left\langle J^{-1} x^{*}-x, y^{*}\right\rangle \leq V\left(x, x^{*}+y^{*}\right)
$$

for all $x \in E$ and $x^{*}, y^{*} \in E^{*}$.

The following lemmas give us some nice properties of real sequences.

Lemma 2.9.([25]) Assume that $\left\{a_{n}\right\}$ is a sequence of nonnegative real numbers such that

$$
a_{n+1} \leq\left(1-\alpha_{n}\right) a_{n}+b_{n}, \quad \forall n \geq 1,
$$

where $\left\{\alpha_{n}\right\}$ is a sequence in $(0,1)$ and $\left\{b_{n}\right\}$ is a sequence such that

(a) $\sum_{n=1}^{\infty} \alpha_{n}=+\infty$;

(b) $\limsup _{n \rightarrow \infty} \frac{b_{n}}{\alpha_{n}} \leq 0$ or $\sum_{n=1}^{\infty}\left|b_{n}\right|<+\infty$.

Then $\lim _{n \rightarrow \infty} a_{n}=0$.

Lemma 2.10.([12]) Let $\left\{\gamma_{n}\right\}$ be a sequence of real numbers such that there exists a subsequence $\left\{\gamma_{n_{j}}\right\}$ of $\left\{\gamma_{n}\right\}$ such that $\gamma_{n_{j}}<\gamma_{n_{j}+1}$ for all $j \in \mathbb{N}$. Then there exists 
a nondecreasing sequence $\left\{m_{k}\right\}$ of $\mathbb{N}$ such that $\lim _{k \rightarrow \infty} m_{k}=\infty$ and the following properties are satisfied by all (sufficiently large) numbers $k \in \mathbb{N}$ :

$$
\gamma_{m_{k}} \leq \gamma_{m_{k}+1} \text { and } \gamma_{k} \leq \gamma_{m_{k}+1}
$$

In fact, $m_{k}$ is the largest number $n$ in the set $\{1,2, \ldots, k\}$ such that the condition $\gamma_{n}<\gamma_{n+1}$ holds.

Recall that a sequence of mappings $\left\{T_{n}\right\}_{n=1}^{\infty}$ of $C$ with $\cap_{n=1}^{\infty} F\left(T_{n}\right) \neq \emptyset$ is said to satisfy the AKTT-condition [3],[15] if, for any bounded subset $B$ of $C$,

$$
\sum_{n=1}^{\infty} \sup _{z \in B}\left\{\left\|J T_{n+1} z-J T_{n} z\right\|\right\}<\infty .
$$

Lemma 2.11.([15]) Let $E$ be a reflexive and strictly convex Banach space whose norm is Fréchet differentiable, let $C$ be a nonempty subset of $E$, and let $\left\{T_{n}\right\}$ be a sequence of mappings from $C$ into $E$ satisfying the AKTT-condition with respect to $B \subset C$. Then there exists a mapping $T: B \rightarrow E$ such that

$$
T x=\lim _{n \rightarrow \infty} T_{n} x \quad \forall x \in B
$$

and $\lim _{n \rightarrow \infty} \sup _{z \in B}\left\{\left\|J T z-J T_{n} z\right\|\right\}=0$.

In the sequel, we say that $\left(\left\{T_{n}\right\}, T\right)$ satisfies the AKTT-condition if $\left\{T_{n}\right\}_{n=1}^{\infty}$ satisfies the AKTT-condition and $T$ is defined by $(2.3)$ with $\cap_{n=1}^{\infty} F\left(T_{n}\right)=F(T)$.

\section{Strong Convergence Theorem for a Countable Family of Strongly Relatively Nonexpansive Mappings}

In this section, we prove a strong convergence theorem for strongly relatively nonexpansive mappings in uniformly convex and uniformly smooth Banach spaces. To this end, we need the following proposition.

Proposition 3.1.([16]) Let $C$ be a nonempty, closed and convex subset of a smooth, strictly convex and reflexive Banach space $E$ and $T$ be a relatively nonexpansive mapping from $C$ into $E$. If $\left\{x_{n}\right\}$ is a bounded sequence such that $\lim _{n \rightarrow \infty} \| x_{n}-$ $T x_{n} \|=0$ and $\hat{x}=\Pi_{F(T)}(x)$, then

$$
\limsup _{n \rightarrow \infty}\left\langle J x-J \hat{x}, x_{n}-\hat{x}\right\rangle \leq 0 .
$$

Theorem 3.2. Let $C$ be a nonempty, closed and convex subset of a uniformly convex and uniformly smooth Banach space E. Let $\left\{T_{n}\right\}_{n=1}^{\infty}: C \rightarrow C$ be a sequence of strongly relatively nonexpansive mappings such that $F=\cap_{n=1}^{\infty} F\left(T_{n}\right) \neq \emptyset$. Suppose that $u \in C$ and define the sequence $\left\{x_{n}\right\}$ as follows: $x_{1} \in C$ and

$$
x_{n+1}=\Pi_{C} J^{-1}\left(\alpha_{n} J u+\left(1-\alpha_{n}\right) J T_{n} x_{n}\right), \quad \forall n \geq 1,
$$

where $\left\{\alpha_{n}\right\} \subset(0,1)$ satisfying $\lim _{n \rightarrow \infty} \alpha_{n}=0$ and $\sum_{n=1}^{\infty} \alpha_{n}=\infty$. If $\left(\left\{T_{n}\right\}, T\right)$ satisfies the AKTT-condition, then $\left\{x_{n}\right\}$ converges strongly to $\Pi_{F}(u)$, where $\Pi_{F}$ is 
the generalized projection of $E$ onto $F$.

Proof. We first see that $F$ is closed and convex by Lemma 2.2. Let $u \in C$ and put $p=\Pi_{F}(u)$ and $z_{n}=J^{-1}\left(\alpha_{n} J u+\left(1-\alpha_{n}\right) J T_{n} x_{n}\right)$ for all $n \in \mathbb{N}$. So, by Lemma 2.6, we have

$$
\begin{aligned}
\phi\left(p, x_{n+1}\right) & \leq \phi\left(p, z_{n}\right) \\
& \leq \alpha_{n} \phi(p, u)+\left(1-\alpha_{n}\right) \phi\left(p, T_{n} x_{n}\right) \\
& \leq \alpha_{n} \phi(p, u)+\left(1-\alpha_{n}\right) \phi\left(p, x_{n}\right) .
\end{aligned}
$$

By induction, we can show that $\left\{\phi\left(p, x_{n}\right)\right\}$ is bounded and thus $\left\{x_{n}\right\}$ is also bounded.

We next show that if there exists a subsequence $\left\{x_{n_{k}}\right\}$ of $\left\{x_{n}\right\}$ such that

$$
\lim _{k \rightarrow \infty}\left(\phi\left(p, x_{n_{k}+1}\right)-\phi\left(p, x_{n_{k}}\right)\right)=0,
$$

then

$$
\lim _{k \rightarrow \infty}\left(\phi\left(p, T_{n_{k}} x_{n_{k}}\right)-\phi\left(p, x_{n_{k}}\right)\right)=0
$$

Since $\alpha_{n_{k}} \rightarrow 0$

$$
\lim _{k \rightarrow \infty}\left\|J z_{n_{k}}-J T_{n_{k}} x_{n_{k}}\right\|=\lim _{k \rightarrow \infty} \alpha_{n_{k}}\left\|J u-J T_{n_{k}} x_{n_{k}}\right\|=0 .
$$

Since $J$ is uniformly norm-to-norm continuous on bounded subsets of $E$, so is $J^{-1}$. It follows that

$$
\lim _{k \rightarrow \infty}\left\|z_{n_{k}}-T_{n_{k}} x_{n_{k}}\right\|=0 .
$$

Since $E$ is uniformly smooth and uniformly convex, by Lemma $2.7, \Pi_{C}$ is uniformly norm-to-norm continuous on bounded sets. So we obtain

$$
\lim _{k \rightarrow \infty}\left\|x_{n_{k}+1}-T_{n_{k}} x_{n_{k}}\right\|=\lim _{k \rightarrow \infty}\left\|\Pi_{C} z_{n_{k}}-\Pi_{C} T_{n_{k}} x_{n_{k}}\right\|=0
$$

and hence

$$
\lim _{k \rightarrow \infty}\left\|J x_{n_{k}+1}-J T_{n_{k}} x_{n_{k}}\right\|=0 .
$$

Furthermore, $\lim _{k \rightarrow \infty} \phi\left(x_{n_{k}+1}, T_{n_{k}} x_{n_{k}}\right)=0$. Indeed, by definition of $\phi$, we observe that

$$
\begin{aligned}
\phi\left(x_{n_{k}+1}, T_{n_{k}} x_{n_{k}}\right) & =\left\|x_{n_{k}+1}\right\|^{2}-2\left\langle x_{n_{k}+1}, J T_{n_{k}} x_{n_{k}}\right\rangle+\left\|T_{n_{k}} x_{n_{k}}\right\|^{2} \\
& =\left\langle x_{n_{k}+1}, J x_{n_{k}+1}-J T_{n_{k}} x_{n_{k}}\right\rangle+\left\langle T_{n_{k}} x_{n_{k}}-x_{n_{k}+1}, J T_{n_{k}} x_{n_{k}}\right\rangle .
\end{aligned}
$$

It follows from (3.1) and (3.2) that $\lim _{k \rightarrow \infty} \phi\left(x_{n_{k}+1}, T_{n_{k}} x_{n_{k}}\right)=0$. On the other hand, by Remark 2.1 (ii), we have

$$
\begin{aligned}
& \phi\left(p, T_{n_{k}} x_{n_{k}}\right)-\phi\left(p, x_{n_{k}}\right) \\
= & \left(\phi\left(p, x_{n_{k}+1}\right)-\phi\left(p, x_{n_{k}}\right)\right)+\left(\phi\left(p, T_{n_{k}} x_{n_{k}}\right)-\phi\left(p, x_{n_{k}+1}\right)\right) \\
= & \left(\phi\left(p, x_{n_{k}+1}\right)-\phi\left(p, x_{n_{k}}\right)\right)+\phi\left(x_{n_{k}+1}, T_{n_{k}} x_{n_{k}}\right) \\
& +2\left\langle p-x_{n_{k}+1}, J x_{n_{k}+1}-J T_{n_{k}} x_{n_{k}}\right\rangle .
\end{aligned}
$$


It follows that

$$
\lim _{k \rightarrow \infty}\left(\phi\left(p, T_{n_{k}} x_{n_{k}}\right)-\phi\left(p, x_{n_{k}}\right)\right)=0 .
$$

We next consider the following two cases.

Case 1. $\phi\left(p, x_{n+1}\right) \leq \phi\left(p, x_{n}\right)$ for all sufficiently large $n$. Hence the sequence $\left\{\phi\left(p, x_{n}\right)\right\}$ is bounded and nonincreasing. So we have $\lim _{n \rightarrow \infty} \phi\left(p, x_{n}\right)$ exists. This shows that $\lim _{n \rightarrow \infty}\left(\phi\left(p, x_{n+1}\right)-\phi\left(p, x_{n}\right)\right)=0$ and hence

$$
\lim _{n \rightarrow \infty}\left(\phi\left(p, T_{n} x_{n}\right)-\phi\left(p, x_{n}\right)\right)=0 .
$$

Since $T$ is strongly relatively nonexpansive,

$$
\lim _{n \rightarrow \infty} \phi\left(T_{n} x_{n}, x_{n}\right)=0 .
$$

By Lemma 2.3, we have

$$
\lim _{n \rightarrow \infty}\left\|x_{n}-T_{n} x_{n}\right\|=0
$$

Moreover, we also have

$$
\begin{aligned}
\left\|x_{n}-T x_{n}\right\| & \leq\left\|x_{n}-T_{n} x_{n}\right\|+\left\|T_{n} x_{n}-T x_{n}\right\| \\
& \leq\left\|x_{n}-T_{n} x_{n}\right\|+\sup _{z \in\left\{x_{n}\right\}}\left\|T_{n} z-T z\right\| .
\end{aligned}
$$

Since $\left(\left\{T_{n}\right\}, T\right)$ satisfies the AKTT-condition, by Lemma 2.11 , it follows that

$$
\lim _{n \rightarrow \infty}\left\|x_{n}-T x_{n}\right\|=0 .
$$

Proposition 3.1 yields that

$$
\limsup _{n \rightarrow \infty}\left\langle J u-J p, x_{n}-p\right\rangle \leq 0 .
$$

It also follows that

$$
\limsup _{n \rightarrow \infty}\left\langle J u-J p, T x_{n}-p\right\rangle \leq 0 .
$$

Finally, we show that $x_{n} \rightarrow p$. Using Lemma 2.8, we see that

$$
\begin{aligned}
& \phi\left(p, x_{n+1}\right) \leq \phi\left(p, z_{n}\right) \\
= & V\left(p, \alpha_{n} J u+\left(1-\alpha_{n}\right) J T_{n} x_{n}\right) \\
\leq & V\left(p, \alpha_{n} J u+\left(1-\alpha_{n}\right) J T_{n} x_{n}-\alpha_{n}(J u-J p)\right)+\left\langle\alpha_{n}(J u-J p), z_{n}-p\right\rangle \\
= & V\left(p, \alpha_{n} J p+\left(1-\alpha_{n}\right) J T_{n} x_{n}\right)+\alpha_{n}\left\langle J u-J p, z_{n}-p\right\rangle \\
\leq & \alpha_{n} V(p, J p)+\left(1-\alpha_{n}\right) V\left(p, J T_{n} x_{n}\right)+\alpha_{n}\left\langle J u-J p, z_{n}-p\right\rangle \\
= & \left(1-\alpha_{n}\right) \phi\left(p, T_{n} x_{n}\right)+\alpha_{n}\left\langle J u-J p, z_{n}-p\right\rangle \\
\leq & \left(1-\alpha_{n}\right) \phi\left(p, x_{n}\right)+\alpha_{n}\left\langle J u-J p, z_{n}-p\right\rangle \\
= & \left(1-\alpha_{n}\right) \phi\left(p, x_{n}\right)+\alpha_{n}\left(\left\langle J u-J p, z_{n}-T x_{n}\right\rangle+\left\langle J u-J p, T x_{n}-p\right\rangle\right) .
\end{aligned}
$$


Set $a_{n}=\phi\left(p, x_{n}\right)$ and $b_{n}=\alpha_{n}\left(\left\langle J u-J p, z_{n}-T x_{n}\right\rangle+\left\langle J u-J p, T x_{n}-p\right\rangle\right)$. We see that $\limsup _{n \rightarrow \infty} \frac{b_{n}}{\alpha_{n}} \leq 0$. By Lemma 2.9, since $\sum_{n=1}^{\infty} \alpha_{n}=\infty$, we conclude that $\lim _{n \rightarrow \infty} \phi\left(p, x_{n}\right)=0$. Hence $x_{n} \rightarrow p$ as $n \rightarrow \infty$.

Case 2. there exists a subsequence $\left\{\phi\left(p, x_{n_{j}}\right)\right\}$ of $\left\{\phi\left(p, x_{n}\right)\right\}$ such that $\phi\left(p, x_{n_{j}}\right)<\phi\left(p, x_{n_{j}+1}\right)$ for all $j \in \mathbb{N}$. By Lemma 2.10, there exists a strictly increasing sequence $\left\{m_{k}\right\}$ of positive integers such that the following properties are satisfies by all numbers $k \in \mathbb{N}$ :

$$
\phi\left(p, x_{m_{k}}\right) \leq \phi\left(p, x_{m_{k}+1}\right) \text { and } \phi\left(p, x_{k}\right) \leq \phi\left(p, x_{m_{k}+1}\right) .
$$

So we have

$$
\begin{aligned}
0 & \leq \lim _{k \rightarrow \infty}\left(\phi\left(p, x_{m_{k}+1}\right)-\phi\left(p, x_{m_{k}}\right)\right) \\
\leq & \limsup _{n \rightarrow \infty}\left(\phi\left(p, x_{n+1}\right)-\phi\left(p, x_{n}\right)\right) \\
\leq & \limsup _{n \rightarrow \infty}\left(\phi\left(p, z_{n}\right)-\phi\left(p, x_{n}\right)\right) \\
& \leq \limsup _{n \rightarrow \infty}\left(\alpha_{n} \phi(p, u)+\left(1-\alpha_{n}\right) \phi\left(p, T_{n} x_{n}\right)-\phi\left(p, x_{n}\right)\right) \\
& =\limsup _{n \rightarrow \infty}\left(\alpha_{n}\left(\phi(p, u)-\phi\left(p, T_{n} x_{n}\right)\right)+\left(\phi\left(p, T_{n} x_{n}\right)-\phi\left(p, x_{n}\right)\right)\right) \\
& \leq \limsup _{n \rightarrow \infty} \alpha_{n}\left(\phi(p, u)-\phi\left(p, T_{n} x_{n}\right)\right)=0 .
\end{aligned}
$$

This shows that

$$
\lim _{k \rightarrow \infty}\left(\phi\left(p, x_{m_{k}+1}\right)-\phi\left(p, x_{m_{k}}\right)\right)=0 .
$$

Following the proof line in Case 1, we can show that

$$
\limsup _{k \rightarrow \infty}\left\langle J u-J p, T x_{m_{k}}-p\right\rangle \leq 0
$$

and

$\phi\left(p, x_{m_{k}+1}\right) \leq\left(1-\alpha_{m_{k}}\right) \phi\left(p, x_{m_{k}}\right)+\alpha_{m_{k}}\left(\left\langle J u-J p, z_{m_{k}}-T x_{m_{k}}\right\rangle+\left\langle J u-J p, T x_{m_{k}}-p\right\rangle\right)$.

This implies

$$
\begin{aligned}
\alpha_{m_{k}} \phi\left(p, x_{m_{k}}\right) \leq & \phi\left(p, x_{m_{k}}\right)-\phi\left(p, x_{m_{k}+1}\right) \\
& +\alpha_{m_{k}}\left(\left\langle J u-J p, z_{m_{k}}-T x_{m_{k}}\right\rangle+\left\langle J u-J p, T x_{m_{k}}-p\right\rangle\right) . \\
\leq & \alpha_{m_{k}}\left(\left\langle J u-J p, z_{m_{k}}-T x_{m_{k}}\right\rangle+\left\langle J u-J p, T x_{m_{k}}-p\right\rangle\right) .
\end{aligned}
$$

Hence $\lim _{k \rightarrow \infty} \phi\left(p, x_{m_{k}}\right)=0$. Using this and (3.4) together, we conclude that

$$
\limsup _{k \rightarrow \infty} \phi\left(p, x_{k}\right) \leq \lim _{k \rightarrow \infty} \phi\left(p, x_{m_{k}+1}\right)=0 .
$$


This completes the proof.

Remark 3.3. In 2011, Nilsrakoo-Saejung [16] investigated a Halpern-Mann iterations for relatively nonexpansive mappings in uniformly convex and uniformly smooth Banach spaces. So it is interesting whether a Halpern's iteration works for a class of relatively nonexpansive mappings.

Acknowledgments. The authors wish to thank Chiang Mai University, Thailand for financial supports.

\section{References}

[1] Y. I. Alber, Metric and generalized projection operators in Banach spaces: properties and applications, In: Kartsatos, A. G. (ed.) Theory and Applications of Nonlinear Operator of Accretive and Monotone Type, Marcel Dekker, New York (1996), 15-50.

[2] K. Aoyama, F. Kohsaka and W. Takahashi, Strongly relatively nonexpansive sequences in Banach spaces and applications, J. Fixed Point Theory Appl., 5(2009), 201-225.

[3] K. Aoyama, Y. Kimura, W. Takahashi and M. Toyoda, Approximation of common fixed points of a countable family of nonexpansive mappings in a Banach space, Nonlinear Anal., 67(2007), 2350-2360.

[4] R. E. Bruck and S. Reich, Nonexpansive projections and resolvents of accretive operators in Banach spaces, Houston J. Math., 3(1977), 459-470.

[5] Y. Censor and S. Reich, Iterations of paracontractions and firmly nonexpansive operators with applications to feasibility and optimization, Optimization 37(1996), 323-339.

[6] C. E. Chidume and C. O. Chidume, Iterative approximation of fixed points of nonexpansive mappings, J. Math. Anal. Appl., 318(2006), 288-295.

[7] Y. J. Cho, S. M. Kang and H. Zhou, Some control conditions on iterative methods, Comm. Appl. Nonlinear Anal., 12(2005), 27-34.

[8] B. Halpern, Fixed points of nonexpanding maps, Bull. Amer. Math. Soc., 73(1967), 957-961.

[9] S. Kamimura and W. Takahashi, Strong convergence of a proximal-type algorithm in a Banach space, SIAM J. Optim., 13(2002), 938-945.

[10] F. Kohsaka and W. Takahashi, Strong convergence of an iterative sequence for maximal monotone operators in a Banach space, Abstr. Appl. Anal., 2004(2004), 239-249.

[11] P. L. Lions, Approximation de points fixes de contractions, C.R. Acad. Sci. Paris Ser. A-B., 284(1977), A1357-A1359.

[12] P. E. Maingé, The viscosity approximation process for quasi-nonexpansive mappings in Hilbert spaces, Comput. Math. Appl., 59(2010), 74-79.

[13] S. Matsushita and W. Takahashi, Weak and strong convergence theorems for relatively nonexpansive mappings in Banach spaces, Fixed Point Theory Appl., 2004(2004), 3747. 
[14] S. Matsushita and W. Takahashi, A strong convergence theorem for relatively nonexpansive mappings in a Banach space, J. Approx. Theor., 134(2005), 257-266.

[15] W. Nilsrakoo and S. Saejung, Strong convergence to common fixed points of countable relatively quasi-nonexpansive mappings, Fixed Point Theory Appl., 2008(2008), Article ID 312454.

[16] W. Nilsrakoo and S. Saejung, Strong convergence theorems by Halpern-Mann iterations for relatively nonexpansive mappings in Banach spaces, Appl. Math. Comput., $\mathbf{2 1 7}(2011)$, 6577-6586.

[17] S. Reich, Approximating fixed points of nonexpansive mappings, PanAmer. Math. J., 4(1994), 23-28.

[18] S. Reich, A weak convergence theorem for the alternating method with Bregman distance, In: Kartsatos, A. G. (ed.) Theory and Applications of Nonlinear Operator of Accretive and Monotone Type, Marcel Dekker, New York (1996), 313-318.

[19] S. Saejung, Halpern's iteration in Banach spaces, Nonlinear Anal., 73(2010), 34313439.

[20] N. Shioji and W. Takahashi, Strong convergence of approximated sequences for nonexpansive mapping in Banach spaces, Proc. Amer. Math. Soc., 125(1997), 3641-3645.

[21] T. Suzuki, A sufficient and necessary condition for Halpern-type strong convergence to fixed points of nonexpansive mappings, Proc. Amer. Math. Soc., 135(2007), 99-106.

[22] W. Takahashi, Nonlinear Functional Analysis, Yokohama Publishers, Yokohama (2000).

[23] R. Wittmann, Approximation of fixed points of nonexpansive mappings, Arch. Math., 58(1992), 486-491.

[24] H. K. Xu, Another control condition in an iterative method for nonexpansive mappings, Bull. Austral. Math. Soc., 65(2002), 109-113.

[25] H. K. Xu, An iterative approach to quadratic optimization, J. Optim. Theory Appl., 116(2003), 659-678. 